\title{
Impact of Mobile Telephone on Maternal Health Service Care: A Case of Njoro Division
}

\author{
Tsimbiri Fedha \\ Egerton University, Nakuru, Kenya \\ Email: tsimbiri2005@yahoo.com \\ Received 16 March 2014; revised 11 May 2014; accepted 21 May 2014 \\ Copyright (C) 2014 by author and Scientific Research Publishing Inc. \\ This work is licensed under the Creative Commons Attribution International License (CC BY). \\ http://creativecommons.org/licenses/by/4.0/

\section{Open Access}

\begin{abstract}
Every minute a woman dies due to pregnancy related complications globally, and half of these deaths occur in the developing countries. Despite knowing the main causes of these deaths, maternal mortality has remained high especially in Sub-Saharan Africa with 536,000 deaths annually. One of the main challenges is access to maternal health services. This study aims at assessing whether mobile telephone will improve uptake of selected maternal health services by expectant mothers at Njoro and Nessuit Health centers in Njoro Division, Nakuru. A total of 397 women were recruited between April 2012 and July 2012 and randomly categorized into two groups for follow up. One group of 191 women were routinely given prompts and advice about their health and scheduled visits while the other group of 206 women were allowed to continue with routine antenatal visits with no mobile telephone support. The results show $7.4 \%$ of those followed up had less than 4 antenatal visits while $18.6 \%$ of those not followed up had less than 4 visits $P$ value 0.002 which shows there was a significantly higher proportion of women on follow up who had more than 4 antenatal visits. There was a significantly higher proportion of women on follow up who received diet and place of delivery counseling, malarial prophylaxis, iron and vitamin supplements and deworming drugs. There was however no difference in those who received tetanus toxoid and HIV counseling. $\mathbf{8 8 . 0} \%$ of the cases on follow up gave birth in a hospital as compared to $72.8 \%$ of those not on follow up with a $P$ value of 0.000 which indicates strong association. Overall hospital delivery was $\mathbf{8 0 . 1 \%}$ for this group a value much higher than national figures of $\mathbf{4 4 \%}$. Women provided with mobile telephone support are more likely to follow the scheduled antenatal advice and use the services as recommended than those who do not receive any support. Therefore mobile telephone should be used routinely to improve antenatal service uptake and communication with health providers.
\end{abstract}

\section{Keywords}

Maternal Health, Antenatal Care, Mobile Phone Use 


\section{Introduction}

Every minute a woman dies globally and half of these deaths occur in Africa due to pregnancy related causes [1]. Despite improved health care systems, many women in the developing world and especially Sub Saharan Africa lack access to maternal health care which is one of the targets of millennium development goal five (MDG 5). Access to maternal care is limited due to cost, poor roads, distance, lack of proper information, inadequate staff and supplies among others.

Risks of mortality for women and their babies are highest at the time of birth while statistics show that approximately 536,000 women of reproductive age die each year due to pregnancy-related complications [1]. Of these deaths, 99\% occur in low-income countries, where fertility rates are higher and a woman's life time risk of dying during pregnancy and childbirth is over 400 times higher than in developed countries [2]. According to UNFPA report 2008 more than 60 million women globally deliver at home without any skilled health care and USAID Health 2008 report shows that about 4 million babies die within first month of life (neonatal period) while 3 million end up as still births [2] [3]. While maternal mortality has declined since 1990, by 26 percent in Latin America and 20 percent in Asia, it has only fallen by 2 percent in Sub-Sahara Africa [4]. The maternal mortality ratio (MMR) in Kenya during the 2008/9 Kenya Demographic Health Survey (KDHS) was estimated at 488 per 100,000 live births, which, though not statistically significant, was higher than the figure of 414 per 100,000 live births, which was reported in the 2003 KDHS [5] [6].

Over 20 million girls and women suffer from morbidities arising from childbirth annually [7]. It is estimated that $75 \%$ of the maternal deaths that occur in the world would be prevented if adequate interventions and access to health care was put in place [8]. The main causes of maternal mortality over years are known as the big five i.e. hemorrhage, sepsis, hypertensive diseases of pregnancy, abortion and obstructed labor [9]. Apart from the last two, the others may be predictable but not necessarily prevented. The challenge therefore lies not only in the treatment of the main causes but also in preventing and providing quality and timely health care to pregnant women.

Access to quality maternal care is viewed as one of the pillars in reducing maternal and neonatal mortality. MDG 5 aims at reducing maternal mortality by three quarters between 1990 and 2015 and providing universal access to reproductive health care by 2015 [10]. One of the indicators of access is the percentage of births attended by skilled health workers which remains low in developing countries for example in Southern Asia (45\%) and Sub-Saharan Africa (46\%) - the two regions with the greatest number of maternal deaths [11]. In Kenya, only $40 \%$ of pregnant women attend antenatal care services and even less deliver in hospitals under care of qualified health providers (KDHS 2008-7). This leaves about 60\% who deliver at home by either relatives or traditional birth attendants. Most women will tend to present late increasing morbidity and mortality. Although adequate and efficient management of pregnancy and its complications are crucial in reducing maternal and neonatal mortality, access and quality health care play a significant part.

Various barriers prevent women from accessing maternal health services. These include cost, distance, poor infrastructure, lack of information and service provider attitudes. There is also shortage of medical personnel in developing countries and especially in the rural areas. On average there are only 2.3 health providers for every 1000 people in Africa compared to 24.8 health workers in America [12]. Despite having 25\% of the global disease burden, Africa has only $3 \%$ of the world's health work force and whereas $50 \%$ of the world's population lives in rural areas, less than $25 \%$ of the doctors and $38 \%$ of the nurses work in the rural areas [12] [13]. WHO recommends 2 physicians for every 10,000 people. Kenya has a ratio of 1:10,000. There is a need to develop strategies that reduce barriers for health care access.

The emergence of mobile telephone technology has improved service delivery, information transfer, businesses, banking and changed ways people communicate in the world. It is estimated that traffic flow will increase 18-fold between 2011 and 2012 and that by 2016; there will be 10 billion mobile devices in the world [14]. Mobile telephone technology is currently widely used in the world to enhance health care delivery. The most common activity is creation of call centers which respond to patient inquiries, and later there are Short Message Texts (SMS) which advise and alert clients on appointments, when to take medications and assessing treatment compliance etc. Several initiatives have been launched that utilize mobile technology to reach clients in far off areas. A mobile device technology initiative called mHealth has been adopted globally with varying country uptake. Rural doctors in China are able to partner with specialists in urban areas and at the same time access client information and data through mobile software [15]. Through mobile telephone application, physicians in India have managed to use broadband connections to review clients in remote areas [16]. An initiative "Text4baby" 
for pregnant women in America has had good impact by informing women how to handle the pregnancy, and problems that may arise and Kaleka et al. 2012 in the study noted that $92 \%$ of the clients in their study were satisfied with the program [17].

In Pakistan, there has been an increase in skilled birth attendance of up to $43 \%$ in remote areas which was $12 \%$ higher than the national average [2]. After launch of a mobile birth notification system that calls a midwife after labor starts Bangladesh has increased skilled attendance at birth to 89\% [18]. In Kenya FHI through a nongovernmental organization called Text to Change launched in April 2010, launched a program in family planning provision and advice that uses mobile telephone technology to provide and advice on family Planning services through Marie Stopes and Family Health Options of Kenya clinics in Nairobi. The service has been widely accepted by clients as it reduces the distance of interaction between service providers and clients [19]. By using mobile phones KEMSA has managed to reduce reporting time for ART use from eight hours to just 5 minutes (qualcomm wireless reach initiative). Kenya Medical Research Institute (KEMRI) in partnership with the Wellcome Trust Research Program of the UK on surveillance of Malaria at the coast by mobile telephone use showed improved data collection, client compliance to treatment and reduced complications [20]. The authors urge for widespread use of mobile phone technology so as to help improve healthcare worker practices and hence service provision to patients. Zurovac et al. 2012 in their study noted the significance of mobile telephone use by increasing communication between clients, health workers in respect of treatment adherence and also disease surveillance, commodity monitoring, post marketing adherence and adherence to guidelines [21]. The communication commission of Kenya's data indicates that in 2008 there were 21.4 million mobile cellular lines in Kenya [22] [23]. This offers a target group to partner in maternal health care provision through mobile services.

The research study sought to establish whether use of mobile technology can increase antenatal service utilization and hospital deliveries in two health facilities in Njoro Division, Nakuru County in Kenya.

\subsection{Statement of the Problem}

Maternal mortality in the Rift Valley is significantly high compared to best managed areas in the world. One of the reasons for poor pregnancy outcome is lack of adequate knowledge on pregnancy complications, delay in patient presentation, and delay in treatment of the obstetric emergencies that can be easily treated even if they may not always be preventable. Use of mobile technology can improve client knowledge base; service uptake and timely management of emerging pregnancy complications thereby improve maternal morbidity and mortality. To achieve the Millennium Development Goal (MDG) 5, the rate can only reduce with integration of the communities' participation by accessing health advice easily, and timely intervention. This research sought to bridge this knowledge gap by establishing whether use of mobile technology can increase antenatal service utilization and hospital deliveries in two health facilities in Njoro Division, Nakuru County in Kenya.

\subsection{Objectives}

The main objective of this study was to assess the impact of mobile technology on maternal health care services utilization and neonatal outcome in Njoro and Nesuit health Centres in Nakuru County in Kenya.

\subsection{Specific Objectives}

1) To determine the socio-demographic characteristics, of clients attending maternal Health services at Njoro Health and Nesuit Health Centers in Rift Valley Province.

2) To determine the impact of mobile telephone support on uptake of selected antenatal services by expectant mothers at the two health centers.

3) To assess the impact of mobile telephone use on place of delivery of the expectant mothers attending antenatal clinic at the two health centers.

4) To assess the impact of mobile telephone use on selected fetal outcomes of expectant mothers attending antenatal clinic at the two health centers.

\subsection{Null Hypothesis}

HO1. Use of mobile telephone in follow up of expectant mothers will not increase uptake of selected antenat- 
al services at the two health centers.

HO2. Use of mobile telephone in follow up of expectant mothers will not increase the chances of hospital delivery by the expectant mothers attending antenatal clinic at the two health centers.

HO3. Use mobile telephone in follow up of expectant mothers will not improve fetal outcomes of expectant mothers attending antenatal clinic at the two health centers.

\section{Methodology}

This was a prospective randomly controlled study. A study sample of expectant clients was selected from those attending antenatal services at Njoro, Nessuit, Huruma and P.C.E.A health centers in Njoro division Rift Valley Province. The sample size was determined in order to have $95 \%$ confidence limits of $5 \%$ maximum error of the estimate, this leads to a requirement of 384 clients. For a no-response expectation, the sample size was increased to 400 clients. A total of 397 clients were recruited between April 2012 and July 2012 and followed up until January 2013. The clients were randomly assigned in two groups by choosing a Yes for those to be offered mobile support i.e. the study group and a No for those who would not be offered mobile support i.e. the control group. The study group of 191 was offered continuous mobile service support, reminded every fortnightly of the next visit to the clinic and given advice on pregnancy updates and advice. The second group of 206 which was the control group was allowed to continue with routine clinics with no mobile advice or updates support. Four trained research assistants, who were clinicians, were recruited to assist in data collection. The principal investigator was responsible in answering and giving advice to the mothers who sought advice. The health care providers from the health facilities were recruited to ensure that there is timely consultation and referral of the clients.

At the entry into the study the participants were informed of the reason of the study, requested to participate and those willing to participate were recruited. They were requested to sign a consent form. Data collection was done by filling in a structured questionnaire at the time of entry into the study by assistance of research assistants. Two weeks after delivery, the clients were again requested to fill another questionnaire that involved information on pregnancy progress, outcome and client satisfaction of services offered. In some instances clients who defaulted in clinic attendance were followed up on mobile or after 6 weeks post-delivery as they brought the infants for immunizations.

Data was analyzed by use of statistical package of social sciences (SPSS) version 17. A descriptive analysis was used to present the results as frequencies and percentages. Bivariate correlation was used to determine significance of effect of mobile use on the various antenatal services provided.

\subsection{Ethical Considerations}

Permission to conduct this study was appoved by Egerton University ethics committee. Request to conduct the study was made to the division health officer and the in charge of the two institutions. Clients attending antenatal clinics in the two study sites were requested to participate in the study after informing them the objective of the study and that by participating they would assist to assess the impact of mobile telephone use in their follow up. Those who consented were requested to sign on the consent form provided by the researcher.

\subsection{Inclusion Criteria}

1) All women attending antenatal care between gestations of 12 to 36 weeks.

2) Those who consented to participate.

\subsection{Exclusion Criteria}

1) Women below 20 weeks gestation.

2) Women above 32 weeks gestation.

\subsection{Limitations of the Study}

The researcher relied on information as entered in the client's attendance. It was assumed that the health provider's entered information each time the client visited the clinic. Lack of entry of some data therefore would affect 
the data collection.

\section{Results}

\subsection{Socio-Demographic Parameters (Table 1)}

The age distribution for the two groups was comparable with $65 \%$ of the participants between the ages of 20 to 29 years. $1 \%$ of the participants were between 15 to 16 years of age with minimum age of 15 while $1.3 \%$ was above 40 years with maximum age of 45 . From this study in Njoro division, many of the women attending antenatal care were between the ages of 20 to 29 years. The under 17 to 19 years comprised $14.9 \%$. The structure therefore had few teenage pregnancy compared to national figures of $18 \%$ and $17 \%$ for Rift valley respectively according to KDHS 2009 [23].

Most of the participants were married $86.6 \%$ and $13.3 \%$ were single.

Participants who had attained upper primary education were (52.6\%) and in secondary they were (36.8\%). Only $9.1 \%$ had attained tertiary education. Most of the participants had attained upper primary (52.6\%) and secondary (36.8\%). Only $1.5 \%$ had lower primary education. Compared to KDHS 2008 where $19 \%$ of the women had no education, the women attending antenatal services in Njoro division have attended some formal education. Women's education is associated with increased antenatal coverage with women with highest education more likely to receive ANC from a doctor than those without [23]. KDHS 2009 also noted that one quarter of women with no education get no antenatal care at all.

Many of the participants $42.6 \%$ earn a salary less than 5000 Kenya shillings per month while $35.3 \%$ have no formal source of income. According to KDHS 2009, it has been noted that one in seven women with lowest wealth quartile does not get any antenatal care. Although many of the women had no formal form of income they attended antenatal care service. The effect of various socio economic factors on the antenatal services use may not hold as there was no statically difference between the two study groups and therefore it can be assumed that the difference in antenatal uptake is due to the intervention given.

Most of the participant's spouses had attained upper primary (33.5\%) and secondary (39.8\%). Spouses who had attained tertiary education were $11.6 \%$. In both groups, the spouse had higher education profile as compared to the women where $11.6 \%$ had tertiary education compared to $9.1 \%$ of the women who had tertiary education. The education profile in this community is commendable although there is a need for the women to strive for higher education for maximum benefits.

\subsection{Previous Pregnancy Outcomes (Parity) (Table 2)}

At time of entry into the study, 5.5\% were 12 to 16 weeks, $11.8 \%$ between 17 to 20 weeks, $24.4 \%$ between 21 to 24 weeks, $24.9 \%$ between 25 to 28 weeks, and $17.9 \%$ between 29 to 32 weeks, while $15.4 \%$ were above 33 weeks. There was no significant difference between the two study groups $\mathrm{P}$ value 0.801 .

Of the participants, 36.3\% were Primi-gravidae, 27\% were Para 1, 18.4\% Para 2, 8.1\% Para 3, and 5.0\% Para 4. Those above Para 5 were $5.4 \%$ with 7 as highest parity. There was no significant difference in the two study groups $P$ value 0.381 .

The participants who had no history of abortions was $94.0 \%$, while $5.0 \%$ had 1 episode of abortion, and $1.1 \%$ had history of more than 1 abortion with highest at 5 . There was no significant difference between the two study groups $\mathrm{P}$ value 0.353 .

Of the participants, $36.5 \%$ were gravida 1 , $24.7 \%$ gravida 2 , $17.6 \%$ gravida 3 and $10.6 \%$ gravida 4 . Only $10.6 \%$ were gravida 5 and above with highest at gravida 8 . There was no significant difference between the two study groups $\mathrm{P}$ value 0.119 . The two groups had similar history of deliveries and gestation at time of entry into the study.

\subsection{Antenatal Service Uptake (Table 3)}

Of the participants, 3.6\% of those in study group had less than 4 antenatal visits while $9.7 \%$ of those in control group had less than 4 visits. There was significant difference between the two study groups $P$ value 0.002 with more women in the study population having more antenatal visits than those in the control group. Of the participants, $7.4 \%$ of those followed up had less than 4 antenatal visits while $18.6 \%$ of those not followed up had less than 4 visits. In sub Saharan Africa antenatal coverage is quite low. In Uganda Mpuungu and Mufubenga 2009 
Table 1. Socio demographic characteristics.

\begin{tabular}{|c|c|c|c|c|}
\hline & & & & \\
\hline & & Study group & Control group & \\
\hline & $15-16$ & $1(0.2 \%)$ & $3(0.8 \%)$ & $4(1.0 \%)$ \\
\hline & $17-19$ & 24 (6.0\%) & 35 (8.8\%) & 59 (14.9\%) \\
\hline & $20-24$ & 73 (18.4\%) & 71 (17.9\%) & $144(36.3 \%)$ \\
\hline & $25-29$ & 53 (13.4\%) & 63 (15.9\%) & 116 (29.2\%) \\
\hline Age cluster & $30-34$ & 28 (7.1\%) & 22 (5.5\%) & 50 (12.6\%) \\
\hline & $35-39$ & $11(2.8 \%)$ & $8(2.0 \%)$ & 19 (4.8\%) \\
\hline & $40-45$ & $1(0.3 \%)$ & $4(1.0 \%)$ & $5(1.3 \%)$ \\
\hline & Totals & 191 (48.0\%) & 206 (52.0\%) & 397 (100.0\%) \\
\hline & Married & 167 (42.1\%) & 177 (44.6\%) & 344 (86.6\%) \\
\hline & Single & $24(6.0 \%)$ & $28(7.1 \%)$ & 52 (13.1\%) \\
\hline & Widowed & $0(0.0 \%)$ & $1(0.3 \%)$ & $1(0.3 \%)$ \\
\hline & Totals & 191 (48.1\%) & 206 (51.9\%) & 397 (100.0\%) \\
\hline & Lower primary & $4(1.0 \%)$ & $2(0.5 \%)$ & $6(1.5 \%)$ \\
\hline & Upper primary & 95 (23.9\%) & 114 (28.7\%) & 209 (52.6\%) \\
\hline Level of education & Secondary & $71(17.9 \%)$ & 75 (18.9\%) & 146 (36.8\%) \\
\hline & Tertiary & $21(5.3 \%)$ & 15 (3.8\%) & 36 (9.1\%) \\
\hline & Totals & 191 (48.1\%) & 206 (51.9\%) & 397 (100.0\%) \\
\hline & Below 5000 & $84(21.2 \%)$ & 85 (21.4\%) & $169(42.6 \%)$ \\
\hline & $5000-10,000$ & 32 (8.1\%) & 31 (7.8\%) & 63 (15.9\%) \\
\hline & $10,001-15,000$ & $6(1.5 \%)$ & $6(1.5 \%)$ & 12 (3.0\%) \\
\hline & $15,001-20,000$ & $3(0.8 \%)$ & $2(0.5 \%)$ & $5(1.3 \%)$ \\
\hline Salary per month & $20,001-30,000$ & $1(0.3 \%)$ & $5(1.3 \%)$ & $6(1.5 \%)$ \\
\hline & $30,001-40,000$ & $1(0.3 \%)$ & $0(0.0 \%)$ & $1(0.3 \%)$ \\
\hline & $40,001-50,000$ & $1(0.3 \%)$ & $0(0.0 \%)$ & $1(0.3 \%)$ \\
\hline & Not applicable & 63 (15.9\%) & 77 (19.4\%) & 140 (35.3\%) \\
\hline & Totals & 191 (48.1\%) & 206 (51.9\%) & 397 (100.0\%) \\
\hline & Lower primary & $0(0 \%)$ & $1(0.3 \%)$ & $1(0.3 \%)$ \\
\hline & Upper primary & 62 (15.6\%) & 71 (17.9\%) & 133 (33.5\%) \\
\hline & Secondary & 72 (18.1\%) & 86 (21.7\%) & 158 (39.8\%) \\
\hline $\begin{array}{l}\text { Level of education of } \\
\text { the spouse }\end{array}$ & Tertiary & $28(7.1 \%)$ & 18 (4.5\%) & $46(11.6 \%)$ \\
\hline & Don't know & $1(0.3 \%)$ & $0(0.0 \%)$ & $1(0.3 \%)$ \\
\hline & NA & $28(7.1 \%)$ & $30(7.6 \%)$ & $58(14.6 \%)$ \\
\hline & Total & 191 (48.1\%) & 206 (51.9\%) & 397 (100.0\%) \\
\hline
\end{tabular}


Table 2. Gestation and previous pregnancies.

\begin{tabular}{|c|c|c|c|c|}
\hline & \multicolumn{3}{|c|}{ Response } & \multirow{2}{*}{ Total } \\
\hline & Categories & Study group & Control group & \\
\hline \multirow[t]{6}{*}{ Gestation cluster } & $12 / 40$ to 16 & $9(2.3 \%)$ & $13(3.3 \%)$ & $22(5.5 \%)$ \\
\hline & $17 / 40$ to $20 / 40$ & $23(5.8 \%)$ & $24(6.0 \%)$ & 47 (11.8\%) \\
\hline & $21 / 40$ to $24 / 40$ & 47 (11.8\%) & $50(12.6 \%)$ & 97 (24.4\%) \\
\hline & $25 / 40$ to $28 / 40$ & 44 (11.1\%) & 55 (13.9\%) & 99 (24.9\%) \\
\hline & $29 / 40$ to $32 / 40$ & $39(9.8 \%)$ & 32 (8.1\%) & $71(17.9 \%)$ \\
\hline & $33 / 40$ to $36 / 40$ & 29 (7.3\%) & $32(8.1 \%)$ & $61(15.4 \%)$ \\
\hline \multirow[t]{8}{*}{ Parity } & 0 & 69 (17.4\%) & 75 (18.9\%) & $144(36.3 \%)$ \\
\hline & 1 & $52(13.1 \%)$ & 55 (13.9\%) & 107 (27.0\%) \\
\hline & 2 & $32(8.1 \%)$ & $41(10.3 \%)$ & 73 (18.4\%) \\
\hline & 3 & $18(4.5 \%)$ & $14(3.5 \%)$ & $32(8.1 \%)$ \\
\hline & 4 & $8(2.0 \%)$ & $12(3.0 \%)$ & $20(5.0 \%)$ \\
\hline & 5 & $5(1.3 \%)$ & $6(1.5 \%)$ & $11(2.8 \%)$ \\
\hline & 6 & $5(1.3 \%)$ & $0(0 \%)$ & $5(1.3 \%)$ \\
\hline & 7 & $2(0.5 \%)$ & $3(0.8 \%)$ & $5(1.3 \%)$ \\
\hline \multirow[t]{5}{*}{ Number of abortion } & 0 & $178(44.8 \%)$ & $195(49.1 \%)$ & $373(94.0 \%)$ \\
\hline & 1 & $9(2.3 \%)$ & $11(2.8 \%)$ & $20(5.0 \%)$ \\
\hline & 2 & $2(0.5 \%)$ & $0(0 \%)$ & $2(0.5 \%)$ \\
\hline & 3 & $1(0.3 \%)$ & $0(0 \%)$ & $1(0.3 \%)$ \\
\hline & 5 & $1(0.3 \%)$ & $0(0 \%)$ & $1(0.3 \%)$ \\
\hline \multirow[t]{9}{*}{ Gravidity } & 1 & $68(17.1 \%)$ & 77 (19.4\%) & 145 (36.5\%) \\
\hline & 2 & 48 (12.1\%) & $50(12.6 \%)$ & $98(24.7 \%)$ \\
\hline & 3 & $29(7.3 \%)$ & 41 (10.3\%) & $70(17.6 \%)$ \\
\hline & 4 & $25(6.3 \%)$ & 17 (4.3\%) & 42 (10.6\%) \\
\hline & 5 & 7 (1.8\%) & 11 (2.8\%) & 18 (4.5\%) \\
\hline & 6 & $4(1.0 \%)$ & 7 (1.8\%) & $11(2.8 \%)$ \\
\hline & 7 & $6(1.5 \%)$ & $0(0 \%)$ & $6(1.5 \%)$ \\
\hline & 8 & $4(1.0 \%)$ & $3(0.8 \%)$ & 7 (1.8\%) \\
\hline & Total & 191 (48.1\%) & 206 (51.9\%) & $397(100.0 \%)$ \\
\hline
\end{tabular}

in their study noted that only 37\% of women attended 4 visits or more [24]. Abosse et al. 2010 in Ethiopia in their study noted that only $42 \%$ of the women attended 4 visits or more [25]. In eastern sudan, Ali et al. 2009 found a coverage of 11\% [26]. In Kenya, the number of women who attend less than four visits is more than half of the women who are pregnant [23]. In this study the general number of women who had attended 4 or more 
Table 3. Number of ante natal visits attended.

\begin{tabular}{cccc}
\hline & \multicolumn{2}{c}{ Response } & \multirow{2}{*}{ Total } \\
\cline { 1 - 2 } Number of antenatal visits & Study group & Control group & \\
\hline 1 & $0(0.0 \%)$ & $1(0.3 \%)$ & $1(0.3 \%)$ \\
3 & $3(0.8 \%)$ & $11(2.8 \%)$ & $14(3.5 \%)$ \\
4 & $11(2.8 \%)$ & $26(6.6 \%)$ & $37(9.4 \%)$ \\
5 & $60(15.2 \%)$ & $80(20.3 \%)$ & $140(35.4 \%)$ \\
7 & $91(23.0 \%)$ & $71(18.0 \%)$ & $162(41.0 \%)$ \\
Total & $23(5.8 \%)$ & $15(3.8 \%)$ & $38(9.6 \%)$ \\
& $3(0.8 \%)$ & $0(0.0 \%)$ & $3(0.8 \%)$ \\
\hline
\end{tabular}

antenatal visits was $87.8 \%$. The variation could be attributed to the fact that the study population was from those already attending clinics unlike in the other studies that looked at pregnant women in the community. There is regional difference in ANC attendance with $60 \%$ of urban women making more than 4 visits unlike rural women where only $44 \%$ attended 4 visits or more overall $47 \%$. In the KDHS 2008-2009 study it was noted that there has been a general decline in women attending ANC 52\% in 2003 to $47 \%$ in 2008-2009 [23]. This indicated a worrisome trend that calls for intervention that will encourage having more regular visits by pregnant women. This study shows a significant difference between the two study groups. P value 0.002 with increase in women $92.6 \%$ of women who were followed up by mobile telephone in number of visits as compared to $82.4 \%$ who were in the control group. Thus we reject the null hypothesis as the mobile use had a significant effect on number of antenatal clinic attendance. Although the overall high antenatal attendance may in part be due to the fact that the sample population was drawn from women already attending the clinic than overall community statistics the increased antenatal service uptake in the study group positively correlate with the intervention taken.

$75.9 \%$ of the cases on follow up had discussed place of delivery while $62.6 \%$ of those not followed up had discussed place of delivery. There was significant difference between the two study groups $\mathrm{P}$ value 0.004 with more women in the study population having discussed the place of delivery than those in the control group. 95.3\% of the cases study group had received counseling on diet as compared to $89.3 \%$ of those in control group. There was significant difference between the two study groups $\mathrm{P}$ value 0.027 with more women in the study population having had a discussion on diet than those in the control group. At the time of delivery, $100 \%$ of the cases in study group had received tetanus toxoid injection as compared to $99.5 \%$ of that not on mobile support. There was no significant difference between the two study groups $\mathrm{P}$ value 0.335 . At time of delivery, $96.3 \%$ of the cases in study group had been counseled on HIV infection in pregnancy as compared to $95.1 \%$ of those in control group. There was no significant difference between the two studies groups P value 0.559 . From the Table 4 above, $39.8 \%$ of the cases in study group had been given vitamin supplements in pregnancy as compared to $23.8 \%$ of those in control group. There was significant difference between the two study groups $\mathrm{P}$ value 0.001 with more women in the study population having used vitamin supplements than those in the control group.

$74.3 \%$ of the cases on follow up had been given de-worming drugs in pregnancy as compared to $59.2 \%$ of those not on follow up. There was significant difference between the two study groups $\mathrm{P}$ value 0.001 with more women in the study population having used drugs for anthelminthic than those in the control group. $91.6 \%$ of the cases on follow up had been given Iron supplements in pregnancy as compared to $87.4 \%$ of those not on follow up. There was no significant difference between the two study groups $P$ value 0.170 . In this table, $80.6 \%$ of the cases on follow up had received Malarial Prophylaxis in pregnancy as compared to $48.5 \%$ of those not on follow up. There was significant difference between the two study groups $\mathrm{P}$ value 0.000 with more women in the study population having used malarial prophylaxis than those in the control group.

Those who were study group had higher rates of tetanus toxoid immunization $100 \%$ and HIV counseling $95.1 \%$ than those in control group i.e. 99.7\% and 93.1\% respectively. Although not statistically significant P values of 
Table 4. Antenatal service uptake.

\begin{tabular}{|c|c|c|c|c|}
\hline & & \multicolumn{2}{|c|}{ Response } & \multirow[b]{2}{*}{ Total } \\
\hline & & Study group & Control group & \\
\hline \multirow{2}{*}{$\begin{array}{l}\text { Discuss where delivery } \\
\text { would take place }\end{array}$} & Yes & 145 (75.9\%) & 129 (62.6\%) & $274(69.0 \%)$ \\
\hline & No & $46(24.1 \%)$ & 77 (37.4\%) & $123(31.0 \%)$ \\
\hline \multirow{2}{*}{ Diet councelling } & Yes & $182(95.3 \%)$ & $184(89.3 \%)$ & 366 (92.2\%) \\
\hline & No & $9(4.7 \%)$ & 22 (10.7\%) & $31(7.8 \%)$ \\
\hline \multirow[t]{2}{*}{ First injection } & Yes & $191(100.0 \%)$ & 205 (99.5\%) & 396 (99.7\%) \\
\hline & No & $0(0.0 \%)$ & $1(0.5 \%)$ & $1(0.3 \%)$ \\
\hline \multirow[t]{2}{*}{ HIV councelling } & Yes & 184 (96.3\%) & 196 (95.1\%) & 380 (95.7\%) \\
\hline & No & 7 (3.7\%) & $10(4.9 \%)$ & $17(4.3 \%)$ \\
\hline \multirow[t]{2}{*}{ Vitamin supplement } & Yes & 76 (39.8\%) & 49 (23.8\%) & 125 (31.5\%) \\
\hline & No & $115(60.2 \%)$ & $157(76.2 \%)$ & 272 (68.5\%) \\
\hline \multirow[t]{2}{*}{ Deworming drugs } & Yes & $142(74.3 \%)$ & 122 (59.2\%) & 264 (66.5\%) \\
\hline & No & $49(25.7 \%)$ & $84(40.8 \%)$ & 133 (33.5\%) \\
\hline \multirow[t]{2}{*}{ Iron supplements } & Yes & 175 (91.6\%) & $180(87.4 \%)$ & 355 (89.4\%) \\
\hline & No & $16(8.4 \%)$ & $26(12.6 \%)$ & $42(10.6 \%)$ \\
\hline \multirow[t]{3}{*}{ Malaria prophilaxis } & Yes & 154 (80.6\%) & $100(48.5 \%)$ & 254 (64.0\%) \\
\hline & No & 37 (19.4\%) & $106(51.5 \%)$ & $143(36.0 \%)$ \\
\hline & Total & 191 (48.1\%) & 206 (51.9\%) & 397 (100.0\%) \\
\hline
\end{tabular}

0.534 and 0.335 respectively all women on follow up received tetanus toxoid. There was significant difference among the two groups in Diet counseling, discussion on place of delivery, vitamin and iron supplements use, treatment for Helminthes and malarial prophylaxis an indication that use of mobile telephone follow up and prompts in this group enhanced service uptake. Given that 5 variables showed an improvement of service uptake against two variables then we reject the null hypothesis. In Pakistan, there was an increase in skilled birth attendance of up to $43 \%$ in remote areas which was $12 \%$ higher than the national average [2]. After launch of a mobile birth notification system that calls a midwife after labor starts Bangladesh has increased skilled attendance at birth to 89\%. In Kenya FHI through a nongovernmental organization called Text to Change launched in April 2010 through Marie Stopes and Family Health Options of Kenya clinics in Nairobi a program in family planning provision and advice has shown wide acceptance by clients as it reduces the distance of interaction between service providers and clients [19]. These findings therefore are in agreement with the findings of this study that has found that positive relationship with mobile telephone use and number of total antenatal visits, antenatal service uptake and hospital delivery and therefore concludes that mobile telephone support and follow of pregnant women should be incorporated for use in the health sector.

The results show that $88.0 \%$ of the cases on follow up gave birth in a hospital as compared to $72.8 \%$ of those not on follow up. There was significant difference in the two groups with a $\mathrm{P}$ value of 0.000 which then implies that follow up through mobile telephone improves skilled delivery attendance. We therefore reject the second null hypothesis since mobile use improved the proportion of women who delivered at the hospital. Overall Hospital delivery was $\mathbf{8 0 . 1 \%}$. Both groups had hospital delivery rates higher than national figures of 44\% KDHS 2009 [23]. Of the cases in study group, 1\% [2] had intra uterine fetal death as compared to 1.5\% [3] of those in control group. There was no significant difference between the two study group with a $\mathrm{P}$ value 0.715 therefore use of mobile telephone did not affect the number of cases who had Intra Uterine fetal deaths (Table 5).

Neonatal deaths among the study group were $1.0 \%$ and that in the control group 3.4\%. Overall neonatal death 
was $2.3 \%$. There was no significant difference in the two study groups $\mathrm{P}$ value 0.269 . Based on a value of 0.269 and 0.715 respectively, the study concluded that there was no statistical significant difference between the two groups in utero and neonatal deaths. National neonatal deaths in Kenya stand at 22 per 1000 live births KHDS 2009 [23]. The figure of 9 for this sample translates to 27.7 deaths per 1000 live births which is much high. Although there was no significant difference in the two groups, cases in study group had lower proportion of neonatal deaths than those in control group. If mobile telephone is scaled up with involvement of all stakeholders i.e. clients, community, and hospital staff, then there is likely to be significant reduction in neonatal deaths.

The proportion of infants who cried immediately at birth in the study population is $97.4 \%$ as compared to $95.6 \%$ among the control group. There was no statistical difference in the infants cry for the two groups P value 0.765 . The variables for fetal outcome i.e. neonatal death, intrauterine death and infants cry at birth showed no difference and hence we accept null hypothesis. Use of mobile phones in follow up did not improve fetal outcome significantly.

\subsection{Mobile Telephone Contribution (Table 6)}

In this study $91.4 \%$ of the mothers had mobile phones. Those who did not have a mobile telephone had at least a member of the family who had a mobile through whom communication could be passed.

\section{Conclusions and Recommendation}

This study shows a high percentage of women attending antenatal clinic have mobile phone. There was a positive correlation between women in study group and the number of antenatal visits before delivery $(96.4 \%$ in

\begin{tabular}{|c|c|c|c|c|}
\hline & & \multicolumn{2}{|c|}{ Response } & \multirow{2}{*}{ Total } \\
\hline & & Study group & Control group & \\
\hline \multirow{2}{*}{ Place of birth } & Hospital & $168(88.0 \%)$ & 150 (72.8\%) & 318 (80.1\%) \\
\hline & Home & $23(12.0 \%)$ & 56 (27.2\%) & 79 (19.9\%) \\
\hline \multirow{3}{*}{ Died after birth } & Yes & $2(1.0 \%)$ & 7 (3.4\%) & $9(2.3 \%)$ \\
\hline & No & 187 (97.9\%) & 196 (95.1\%) & 383 (96.5\%) \\
\hline & $\mathrm{n} / \mathrm{a}$ & 2 (1.0\%) & 3 (1.5\%) & $5(1.3 \%)$ \\
\hline \multirow{5}{*}{ Cry after delivery } & Immediately & $186(97.4 \%)$ & 197 (95.6\%) & 383 (96.5\%) \\
\hline & After 5 minutes & $1(0.5 \%)$ & $3(1.5 \%)$ & $4(1.0 \%)$ \\
\hline & After 10 minutes & $2(1.0 \%)$ & 3 (1.5\%) & $5(1.3 \%)$ \\
\hline & Not applicable & $2(1.0 \%)$ & $3(1.5 \%)$ & $5(1.3 \%)$ \\
\hline & Total & 191 (48.1\%) & 206 (51.9\%) & 397 (100.0\%) \\
\hline
\end{tabular}

Table 6. Women with mobile phones.

\begin{tabular}{|c|c|c|c|}
\hline & \multicolumn{2}{|c|}{ Response } & \multirow{2}{*}{ Total } \\
\hline & Study group & Control group & \\
\hline Own tel no & 176 (92.1\%) & 187 (90.8\%) & 363 (91.4\%) \\
\hline No & 15 (7.9\%) & 19 (9.2\%) & 34 (8.6\%) \\
\hline Total & $191(48.1 \%)$ & 206 (51.9\%) & 397 (100.0\%) \\
\hline
\end{tabular}


study group and $92.3 \%$ in the control P value 0.002$)$, provision of counseling services in HIV (95.3\% in study group and $83.7 \%$ in the control), diet counseling (95.3\% in study group and $83.7 \%$ in the control), place of delivery (75.9 in study group and $62.6 \%$ in the control) those who received tetanus (100\% in study group and 99.5\%), iron (91.6\% and 87.4\%) vitamin supplements (39.8\% and $23.8 \%)$ and anti-helminthes (74.3\% and $59.2 \%)$. The number of women who had been followed up that delivered in hospital was significantly higher than those who did not receive mobile telephone support i.e. $88.0 \%$ and $72.8 \%$ respectively.

I therefore recommend that mobile telephone should be used in antenatal service provision and client follow up to enhance information dissemination, service delivery, client contact and service uptake, medical education on first contact of pregnant women on significance, implications and presentations of medical disorders in pregnancy and need for early presentation should be emphasized by the service providers. The ministry of health and other policy makers should incorporate mobile telephone use in guidelines on client follow up. More research is required in other issues relating to mobile telephone use and maternal health care provision to understand other areas that may impact on acceptability, confidentiality and scope of mobile telephone use in health care.

\section{References}

[1] World Health Organization (2007) Maternal Mortality in 2005: Estimates by WHO, UNICEF, UNFPA and the World Bank.

[2] United Nations Children's Fund (2008) State of the World's Children's 2009: Maternal and Newborn Health. New York.

[3] USAID Health (2008) Maternal and Child Health Updates.

[4] Sing, S., et al. (2009) Adding It up: The Costs and Benefits of Investing in Family Planning and Maternal and Newborn Health. Guttmacher Institute/UNFPA, New York.

[5] Kenya Demographic and Health Survey (2008) Central Bureau of Statistics Nairobi, Kenya. Ministry of Health Nairobi, Kenya.

[6] Kenya Demographic and Health Survey (2003) Central Bureau of Statistics Nairobi, Kenya. Ministry of Health Nairobi, Kenya.

[7] UNICEF (2008) Countdown to 2015 MNCH: The 2008 Report. Tracking Progress in Maternal, Newborn and Child Survival.

[8] Hunt, P. and de Meswuita, J.B. (2007) Reducing Maternal Mortality; the Contribution of the Right to the Highest Attainable Standard of Health. Human Rights Center University of Essex.

[9] Working Together for Health (2006) WHO Report. www.who.int/whr/2006/en/

[10] World Health Organization (WHO) (2010) UNICEF, UNFPA, World Bank. Trends in Maternal Mortality 1990-2008. http://whqlibdoc.who.int/publications/2010/9789241500265_eng.pdf

[11] World Health Organization (2004-2009) Global Health Observancy, Statistical Database.

[12] World Health Organization (2006) The Global Shortage of Health Workers and Its Impact. Fact Sheet No. 02, WHO, Geneva.

[13] World Health Organization (2009) Monitoring the Geographical Distribution of the Health Workforce in Rural and Underserved Areas. Spotlight on Health Workforce Statistics, No. 8, WHO, Geneva.

[14] Cisco Visual Networking Index (2012) Global Mobile Data Traffic Forecast Update, 2011-2016. 1-3.

[15] Qualcomm Wireless Reach Initiative (2011) 3G Mobile Medicine: Connecting Rural and Urban Doctors to Improve Patient Care in China.

[16] Rediff.com (2012) Why Healthcare Sector Is Upbeat about Telemedicine. March 14.

[17] Kaleka, A., et al. (2012) Utilization of Text4baby to Improve Maternal and Infant Outcomes with Interdisplinery Team. Seattle. http://www.fmdrl.org/index.cfm?event=c.accessResources\&rid-3850

[18] Brownlee, C. (2012) mHealth—Can You Hear Me Now? The Magazine of the Johns Hopkins University Bloomberg School of Public Health.

[19] (2010) FHI 360: m4RH Kenya: Results from Pilot Study. http://m4rh.fhi360.org/wp-content/uploads/2012/11/m4RH-Presentation Kenya-Results1.pdf

[20] Dejan, Z., Raymond, K.S., et al. (2010) The Effect of Mobile Phone Text-Message Reminders on Kenyan Health Workers’ Adherence to Malaria Treatment Guidelines: A Cluster Randomised Trial. Lancet, 378, 795-803.

[21] Zurovac, D., et al. (2012) The Effect of Mobile Phone Text-Message Reminders on Kenyan Health Workers’ Adherence to Malaria Treatment Guidelines: A Cluster Randomised Trial. Lancet, 378, 795-803. 
http://dx.doi.org/10.1016/S0140-6736(11)60783-6

[22] Communications Commission of Kenya (2010) Sector Statistics Report Q4 2009/10. http://www.cck.go.ke/resc/statcs.html

[23] Kenya National Bureau of Statistics (2010) Kenya Census 2009 Population and Housing Census Highlights. http://www.knbs.or.ke/Census\%20Results/KNBS\%20Brochure.pdf

[24] Kiwuwa, M.S. and Mufubenga, P. (2009) Use of Antenatal Care, Maternity Services, Intermittent Presumptive Treatment and Insecticide Treated Bed Nets by Pregnant Women in Luwero District, Uganda. Malaria Journal, 7, 44. http://dx.doi.org/10.1186/1475-2875-7-44

[25] Abosse, Z., et al. (2010) Factors Affecting Antenatal Care Service Delivery in Hadiya Zone. Journal of Health Science, 20, 75-82.

[26] Ali, A.A., et al. (2010) Use of Antenatl Care Services in Kassala Eastern Sudan. BMC Pregnancy and Childbirth, 10, 67. http://dx.doi.org/10.1186/1471-2393-10-67

\section{List of Abbreviations and Accronyms}

ART: Anti Retroviral Therapy

CCK: Communication Commission of Kenya

FHI: Family Health International

HIV: Human Immunodeficiency Virus

KDHS: Kenya Demographic Health Survey

KEMRI: Kenya Medical Research Institution

KEMSA: Kenya Medical Supplies Agency

MDG: Millennium Development Goals

MMR: Maternal Mortality Rate

P.C.E.A: Presbyterian Church of East Africa

SMS: Short Message Texts

UNICEF: United Nations Children's Fund

USAID: United States Agency for International Development

WHO: World Health Organisation 